\title{
ESTÁGIO DE ADEQUAÇÃO DAS INFORMAÇÕES CONTÁBEIS ÀS NORMAS INTERNACIONAIS DE CONTABILIDADE NO SETOR DE PETRÓLEO, GÁS E BIOCOMBUSTÍVEIS
}

\section{ACCOUNTING INFORMATION ADEQUACY STAGE TO THE INTERNATIONAL ACCOUNTING STANDARDS IN OIL, GAS, AND BIO-FUEL SECTOR}

\section{ESTADO DE ADECUACIÓN DE LAS INFORMACIONES CONTABLES A LAS NORMAS INTERNACIONALES DE CONTABILIDAD EN EL SECTOR DE PETRÓLEO, GAS Y BIOCOMBUSTIBLES}

\begin{abstract}
RICARDO BIALI RIBEIRO
Mestre em Contabilidade pelo Programa Multiinstitucional e Inter-regional de Pós-Graduação em Ciências Contábeis UnB/UFPB/UFRN; Especialista em Finanças com Ênfase em Controladoria pela Faculdade Natalense para o Desenvolvimento do Rio Grande do Norte (FARN); Professor univesitário para Administração e Ciências Contábeis ricardobiali@yahoo.com.br
\end{abstract}

JOSÉ DIONISIO GOMES DA SILVA

Doutor em Contabilidade e Controladoria pela USP

Professor-Adjunto da UFRN

dionisio@ufrnet.br

\section{RESUMO}

O presente trabalho propôs discutir a seguinte questão: com a adequação da legislação societária brasileira aos padrões internacionais, qual o estágio de divulgação das informações contábeis em empresas do setor de petróleo, gás e biocombustíveis listadas na Bovespa? Visando responder a essa inquietação, é analisado tal estágio, avaliando as informações contábeis divulgadas pelas empresas do setor relativas aos exercícios sociais de 2007 e 2008. Com 
base no comparativo, são elencadas quais adesões foram adotadas pelas empresas à nova legislação societária referente às informações contábeis divulgadas. A metodologia utilizada é de natureza descritiva com abordagem indutiva cujo sítio eletrônico da Bovespa foi a fonte da pesquisa. Os principais resultado encontrados apontam que houve uma adequação antes das

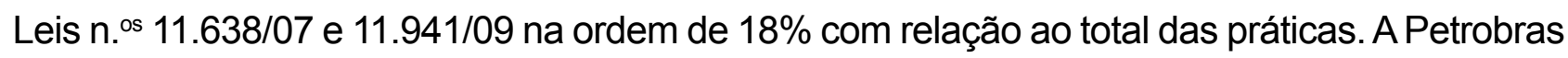
realizou adequação das normas na ordem de 44\%, enquanto as demais companhias representaram uma média de 15\% de adequação. Após a emissão das referidas leis, houve adequação na ordem de $70 \%$. Conclui-se assim que, apesar de a lei não esgotar o direito, as empresas precisaram de substanciais adequações após as Leis n. ${ }^{\text {ss }} 11.638 / 07$ e 11.941/09, para se adequarem ao processo de convergência das normas internacionais de contabilidade.

Palavras-chave: Informação Contábil; Legislação Societária Brasileira; Convergência às Normas Internacionais de Contabilidade; Petróleo, Gás e Biocombustíveis; Bovespa.

\section{ABSTRACT}

The present paper proposes the discussion of the following issues: with the adequacy of Brazilian corporate legislation to international standards, what is the dissemination stage of accounting information on Oil, Gas, and Bio-fuels companies listed in the Bovespa? Aiming at responding to those concerns, such stage is analyzed by evaluating accounting information related to FY of 2007 and 2008 disseminated by firms of the sector. Based on comparison, it is listed which adhesions were adopted by firms related to the new corporate legislation regarding disseminated accounting information. Methodology used is of descriptive nature with inducing approach whose electronic site at Bovespa was the source for the survey. Major outcomes found indicate that there was an adequacy prior to Laws no. 11,638/07 and 11,941/09 of $18 \%$ compared to total practices. Petrobras conducted around $44 \%$ of adequacy to standards, while other firms represented an average of $15 \%$ of adequacy. After issuance of mentioned legislation, there was about $70 \%$ of adequacy. Thus, it was found that despite legislation does not exhaust Law, firms need substantive adequacies after Laws no. 11,638/07 and 11,941/09 in order to conform to the international accounting standards convergence process..

Keywords: Accounting Information; Brazilian Corporate Legislation; Convergence to International Accounting Standards; Oil, Gas, and Bio-Fuels; Bovespa.

\section{RESUMEN}

El presente trabajo propuso discutir la siguiente cuestión: con la adecuación de la legislación societaria brasileña a los estándares internacionales, ¿cuál es el estado de divulgación de 
las informaciones contables en empresas del sector de petróleo, gas y biocombustibles listadas en Bovespa? Visando responder a esa inquietud, es analizado tal estadio, evaluando las informaciones contables divulgadas por las empresas del sector relativas a los ejercicios sociales de 2007 y 2008 . Con base en el comparativo, son relacionadas qué adhesiones fueron adoptadas por las empresas a la nueva legislación societaria referente a las informaciones contables divulgadas. La metodología utilizada es de naturaleza descriptiva con abordaje inductivo cuyo sitio electrónico de Bovespa fue la fuente de la pesquisa. Los principales resultados encontrados apuntan que hubo una adecuación antes de las Leyes n. o 11.638/07 y 11.941/09 del orden del $18 \%$ con relación al total de las prácticas. La Petrobras realizó adecuación de las normas del orden del $44 \%$, mientras que las demás compañías representaron una media del $15 \%$ de adecuación. Después de la emisión de las referidas leyes, hubo adecuación del orden del 70\%. Se concluye así que, a pesar de que la ley no agote el derecho, las empresas precisaron substanciales adecuaciones tras las Leyes n. o 11.638/07 y 11.941/09, para adecuarse al proceso de convergencia de las normas internacionales de contabilidad.

Palabras clave: Información Contable; Legislación Societaria Brasileña; Convergencia a las Normas Internacionales de Contabilidad; Petróleo, Gas y Biocombustibles; Bovespa.

\section{INTRODUÇÃO}

A Contabilidade pode ser conceituada como ciência social aplicada cujo objetivo fundamental é o de prover informações quantitativas e qualitativas de ordem econômicofinanceiras para tomada de decisão. Entretanto, acontecimentos históricos adversos, como por exemplo, a quebra da Bolsa de Valores norte-americana de 1929 e o escândalo contábil e de auditoria também nos EUA, em 2001, comprovaram que existem ruídos de comunicação no mundo corporativo entre a informação contábil e os investidores, e que tais ruídos inviabilizam maiores ganhos nos empreendimentos. Como resposta, no ano de 2001, o Organismo de Normas Internacionais de Contabilidade (International Accounting Standards Board - IASB) e o Conselho Norte-Americano de Contabilidade Financeira (Financial Accounting Standards Board - FASB) estabeleceram uma agenda de convergência das normas internacionais com o objetivo de uniformizar os princípios contábeis através da harmonização de cada sistema contábil regional na tentativa de aprimorar a qualidade da informação contábil que é repassada através de suas respectivas demonstrações.

O Brasil, para não se abster desse processo, iniciou sua convergência às normas internacionais por meio de ato legislativo, sancionado e promulgado pelo Estado. Surgiu assim, em 2000, o Projeto de Lei n. 3.741 , promulgado sete anos depois, através da Lei n. ${ }^{\circ} 11.638$, de 28 de dezembro de 2007, reformulando algumas práticas contábeis contidas na Lei das Sociedades por Ações, a de n. ${ }^{\circ}$ 6.404, de 15 de dezembro de 1976. 
Ocorre que durante o tempo decorrido entre o projeto de reforma contábil e sua efetiva entrada em vigor, por meio de lei, alguns procedimentos contábeis foram modificados pelo IASB, necessitando da atualização por parte da legislação brasileira. Com essa atualização, algumas práticas contábeis abarcadas pela Lei $n .^{\circ} 11.638$ foram modificadas e, até mesmo, revogadas, até surgir, finalmente, em 3 de dezembro de 2008, a Medida Provisória n. ${ }^{\circ} 449$, convertida na Lei n. ${ }^{\circ} 11.941$, de 27 de junho de 2009, alterando alguns dispositivos da legislação tributária federal relativa ao parcelamento de débitos tributários e, também, algumas regras contábeis contidas na Lei das S/A.

Com a nova legislação, a Contabilidade brasileira passou a buscar enquadramento às normas internacionais de contabilidade, consoante se observa, por exemplo, na nova redação dada ao art. 177, § 5o, da Lei n. ${ }^{\circ}$ 6.404/76 "As normas [...] deverão ser elaboradas em consonância com os padrões internacionais de contabilidade adotados nos principais mercados de valores mobiliários (Incluído pela Lei n. ${ }^{\circ} 11.638$, de 2007)".

No mesmo sentido, Azevedo (2009, p. 17) destaca que o "principal objetivo da nova Lei n. ${ }^{0} 11.638 / 2007,[\ldots]$ foi atualizar as regras contábeis brasileiras e aprofundar a harmonização destas com os pronunciamentos internacionais, em especial os emitidos pelo International Accounting Standards Board (IASB)."

Todavia, algumas questões não podem ser deixadas de lado, quais sejam: até que ponto as empresas brasileiras, antes da nova legislação, divulgavam informações contábeis compatíveis com os critérios internacionais oferecidos pelo IASB?

Setores complexos e de alta competitividade necessitaram fazer grandes mudanças no seu modelo de divulgação de informações contábeis para se ajustar às novas regras?

Realmente a nova legislação brasileira absorveu a evolução defendida pelo organismo internacional de contabilidade e até que ponto a nova estrutura legal impactou as informações contábeis divulgadas?

As empresas do setor de petróleo, gás e biocombustíveis que divulgam suas demonstrações tiveram nas alterações da legislação brasileira impacto no modelo de divulgação das informações contábeis ou essas empresas já estavam adaptadas a esse nível de evidenciação em função da competitividade internacional?

Vale salientar a relevância do referido setor à economia por possuir atuação no comércio exterior e ser passível de enquadramentos a modelos mercadológicos desenvolvidos em todo o mundo.

Ante o exposto, surge o seguinte problema de pesquisa: com a adequação da legislação societária brasileira aos padrões internacionais, qual o estágio de divulgação das informações contábeis em empresas do setor de petróleo, gás e biocombustíveis listadas na Bovespa?

A resposta a esta pergunta poderá contribuir para um melhor entendimento do nível de ajuste das empresas brasileiras ao padrão internacional de contabilidade, independen- 


\section{repec}

temente da definição legal, ou seja, se as corporações brasileiras aguardam o escopo jurídico ou, gradativamente, se ajustam às exigências do mercado internacional no tocante à divulgação das informações contábeis.

Como etapas para atingir o objetivo geral e, consequentemente, contribuir para a resposta do problema de pesquisa, foram elencados os seguintes objetivos: analisar o estágio de adequação da nova legislação societária brasileira às normas internacionais de contabilidade; avaliar as informações contábeis divulgadas pelas empresas do setor de petróleo, gás e biocombustíveis relativas aos exercícios sociais de 2007 e 2008; com base no comparativo, elencar quais alterações a nova legislação societária conferiu às informações contábeis divulgadas.

Já em plena ascensão, o processo de convergência das normas internacionais de contabilidade tem condição de trazer aos usuários, principalmente aos investidores e aos provedores de capital, uma aproximação do valor contábil das empresas a valores mercadológicos negociáveis. Para corroborar com isso, Niyama (2008) afirma que a busca por uniformidade nos critérios contábeis ao redor do mundo proporciona uma maior compreensão da linguagem e comparabilidade das informações contábeis. A grande questão é evidenciar quais atualizações ocorreram com a emissão das novas normas contábeis até o momento para as empresas.

O setor da economia brasileira escolhido foi o das empresas petrolíferas com grande relevância no Produto Interno Bruto (PIB) e na economia nacional. Esse setor justifica-se quando se constata que grandes negócios são transacionados através do petróleo, envolvendo elevado volume de operações financeiras e, consequentemente, de diversas transações contábeis exigidas para atender à demanda informacional. Não obstante, o setor também atua em ambiente de comércio exterior, o que naturalmente pode levar a uma necessidade de transmitir suas informações em nível igualitário e padronizado.

Para que se possa visualizar a importância do setor, o Instituto Brasileiro de Geografia e Estatística (IBGE), em seu sítio eletrônico, no ano de 2008, revelou que foram gerados mais de 50.000 empregos formais diretos no setor, que, além disso, é responsável por $10 \%$ do PIB brasileiro. Ainda, segundo o sítio eletrônico da U.S. Energy Infor-mation Administration - U.S. EIA (administração norte-americana de informações sobre energia), o Brasil ocupava, até 2008, a $12^{a}$ colocação no ranking mundial de produção de petróleo, a $7^{a}$ colocação no consumo mundial, a $42^{a}$ colocação na importação e a $14^{a}$ colocação na exportação do referido produto.

Importante ainda destacar as perspectivas futuras do setor com a possibilidade de grande crescimento a partir de novas descobertas, como o pré-sal, por exemplo.

No trabalho conclusivo, todas as empresas da amostra foram extraídas da Bovespa, posto que o tema faz referência a empresas sujeitas à Lei das S/A, e a conotação científica está em revelar o conteúdo informacional contido nas demonstrações contábeis publicadas. 


\title{
2. REVISÃO DA LITERATURA
}

\subsection{Importância da Divulgação das Informações Contábeis}

A importância em divulgar informações de ordem econômico-financeiras por parte da contabilidade está no fato de que os usuários (investidores, credores, provedo-res de capital, etc.) necessitam conhecer o que está ocorrendo com a entidade.

\begin{abstract}
Eles usam as demonstrações financeiras para satisfazer suas necessidades de informação. Como por exemplo: a) auxiliar na análise do risco inerente ao investimento e o retorno que ele produz, no caso dos investidores; b) informações sobre a continuidade operacional, no caso de clientes; c) destinação de recursos, no caso do governo e suas agências; e d) informações sobre a evolução do desempenho da entidade e os desenvolvimentos recentes, no caso do público geral. (ERNEST \& YOUNG; FIPECAFI. 2009, p. 3)
\end{abstract}

Sobre a evidenciação (em inglês disclosure) da informação contábil, ludícibus (2009, p. 110) elucida:

[...] disclosure está ligado aos objetivos da Contabilidade, ao garantir informações diferenciadas para os vários tipos de usuários. [...] O Accounting Research Study n. ${ }^{\circ}$, editado pelo AICPA, em 1961, estabeleceu, na página 50: 'Os demonstrativos contábeis deveriam evidenciar o que for necessário, a fim de não torná-los enganosos'. É importante focalizar que esta e outras opiniões sobre o assunto quase sempre insistem no problema de não tornar as demonstrações enganosas para o usuário.

Conforme a Estrutura Conceitual Básica do Comitê de Pronunciamentos Contá-beis brasileiro, as informações de ordem econômico-financeiras divulgadas pela contabilidade necessitam de confiabilidade e credibilidade para que todos os diferentes usuários possam ter acesso ao um mercado competitivo.

Segundo o FASB (1978, § 34), "A divulgação financeira deve prover informação que seja útil à tomada de decisões de investimentos, concessões de créditos, etc., por investidores, credores e outros usuários."

No mesmo sentido do FASB, Schroeder et al. (2009, p. 52. tradução livre) elucidam que:

O SFAC $n^{\circ}$. 5 regula à ordem de critérios de reconhecimentos e orienta sobre qual informação deve ser incorporada às demonstrações contábeis e quando estas informações devem ser reportadas. De acordo com o SFAC $n^{\circ} .5$, um pacote completo de peças contábeis deve apresentar: 1) a posição 
financeira ao final do exercício social; 2) lucros para o período; 3) resultado compreendido para o período; 4) fluxos de caixa durante o período; e 4) investimentos e distribuições realizadas à acionistas durante o exercício.

No Brasil, as demonstrações contábeis são reguladas pela Lei n. ${ }^{\circ}$ 6.404/76 que, em seu artigo 176, prescreve:

"Art. 176. Ao fim de cada exercício social, a Diretoria fará elaborar, com base na escrituração mercantil da companhia, as seguintes demonstrações financeiras, que deverão exprimir com clareza a situação do patrimônio da companhia e as mutações ocorridas no exercício:

I - balanço patrimonial;

II - demonstração dos lucros ou prejuízos acumulados;

III - demonstração do resultado do exercício;

IV - demonstração dos fluxos de caixa;

$\mathrm{V}$ - se companhia aberta, demonstração do valor adicionado.

[...] $\S 4^{\circ}$ As demonstrações serão complementadas por notas explicativas e ou-tros quadros analíticos ou demonstrações contábeis necessários para esclare-cimento da situação patrimonial e dos resultados do exercício."

Além disso, a informação contábil contida nas notas explicativas e quadros complementares (entre os documentos citados incluem-se o parecer de auditoria e o relató-rio da administração) são tão ou mais importantes quanto à informação das próprias demonstrações contábeis, pois é ali que o usuário encontrará o dado processado, ou seja, a informação contábil trazida em minúcias. Além da regulação por parte da Lei das S/A, as empresas divulgam informações de forma espontânea, conforme Souza et al. (2008), as "informações contábeis voluntárias representam o conjunto de informações evidenciadas pelas companhias abertas que vai além das obrigações."

Murcia e Santos (2010) relatam que:

A divulgação voluntária é uma opção, assim como outras opções contábeis realizadas para reconhecimento e mensuração de transações econômicas (assim como o PEPS ou UEPS para avaliação do estoque). Estudos recentes revelaram que diversos são os benefícios de se divulgar informações de forma voluntária.

Matoussi e Chakroun (2009, tradução livre) afirmam que:

A qualidade da evidenciação voluntária contida no reportes anuais, a principal fonte da informação, é hoje em dia um dos maiores problemas no coração da teoria das finanças. As empresas estão deparando com sérias crises de credibilidade e não conseguem ade- 
quação quanto à sua comunicação com os usuários. Por isso, transparência e um melhor nível de evidenciação é fator determinante para uma melhor comunicação aos acionistas. Isso direcionará uma melhor alocação do capital no mercado.

\begin{abstract}
A qualidade da evidenciação voluntária contida no reportes anuais, a principal fonte da informação, é hoje em dia um dos maiores problemas no coração da teoria das finanças. As empresas estão deparando com sérias crises de credibilidade e não conseguem adequação quanto à sua comunicação com os usuários. Por isso, transparência e um melhor nível de evidenciação é fator determinante para uma melhor comunicação aos acionistas. Isso direcionará uma melhor alocação do capital no mercado.
\end{abstract}

Quanto à importância, ressalta-se que a informação disponibilizada pela contabilidade (seja voluntária ou compulsória) deve atender à melhor tomada de decisão possível, dentro das limitações de cada usuário, afora possuir também total credibilidade. Com relação a tais limitações, ludícibus (2009, p. 111) afirma:

[...] não se pode esperar e seria tolice pensar que boas decisões de investimento pudessem emanar de um leitor com vagas noções de Contabilidade e de negócios. A interpretação dos demonstrativos contábeis é tarefa única e exclusivamente reservada aos experts em Contabilidade e Finanças, que deveriam ser os intermediários entre as empresas e os donos dos recursos, assessorando estes últimos nas análises.

Por outro lado, deve ser considerado ainda que o usuário da informação contábil adote um processo de avaliação conjunta com as informações disponibilizadas, devendo a organização utilizar criteriosos instrumentos de divulgação para que a difusão realizada da informação não encaminhe o usuário para vieses não desejados.

\title{
2.2 Normas Internacionais de Contabilidade
}

Em ordem de convergência com o Financial Accounting Standards Board (FASB organismo norte-americano de Contabilidade) o International Accounting Standards Board (IASB - organismo internacional de Contabilidade) emitiu, originalmente em 2003, o IAS de n. 01 que trata da apresentação e divulgação das demonstrações contábeis e demais peças contábeis ${ }^{1}$. Em seu $\S 9$, define que:

As demonstrações contábeis são representações estruturadas da posição financeira e do desempenho da entidade. O objetivo das demonstrações contá-

\footnotetext{
${ }^{1}$ Peças contábeis podem ser conceituadas como termo técnico contábil conforme pesquisa de ludícibus e Lopes (2002) quando conceituaram que tais peças viabilizam, entre outras coisas, estimativas sobre o futuro das empresas.
} 
beis é o de prover informação sobre a posição financeira, desempenho financeiro e fluxos de caixa da entidade, de modo a tornar-se útil a um amplo grupo de usuários no processo de tomada de decisões econômicas. As demonstrações contábeis também devem apresentar os resultados dos recursos aplicados pela administração. Para atingir tais objetivos, as demonstrações contábeis da entidade devem informar sobre: a) ativos; b) passivos); c) patrimônio líquido; d) receitas e despesas, incluindo ganhos e perdas; e) distribuições aos acionistas; e f) fluxos de caixa." (IAS n. ${ }^{\circ}$ 01, 2009. Tradução livre).

Conforme visto e na mesma linha de pensamento, o IASB segue aquilo que pri-meiramente foi observado pelo FASB, na década de 1970, no tocante à divulgação da informação por parte das empresas, para que um amplo grupo de usuários interessados possua, tempestivamente, o mesmo nível de informação. Para tanto, o organismo internacional traçou objetivos e metas, a fim de que isso ocorra e o nível de uniformidade das informações contábeis atinja seu ápice. Tais objetivos e metas são assim elucidados:

De acordo com a constituição do lasb, seus objetivos são: a) desenvolver, no interesse público, um único conjunto de normas contábeis globais de alta qualidade, inteligíveis e exequíveis, que exijam informações de alta qualidade, transparentes e comparáveis nas demonstrações contábeis e em outros relatórios financeiros, para ajudar os participantes do mercado de capital e outros usuários em todo o mundo a tomar decisões econômicas; b) promover o uso e a aplicação rigorosa dessas normas; e c) promover a convergência entre as normas contábeis locais e as Normas Internacionais de Contabilidade de alta qualidade. (NIYAMA; SILVA. 2008, p. 33).

Fica claro que as normas internacionais de contabilidade têm como objetivo primordial aumentar o nível de comparabilidade entre diferentes ambientes empresariais ao redor do mundo.

Sobre diferentes ambientes econômicos Klann et al. (2009) anunciam que:

\begin{abstract}
Essas diferenças podem alterar o valor dos indicadores de desempenho, calculados a partir dessas demonstrações. Com isso pode existir uma assimetria de informação. Dependendo da localização dos usuários, eles poderão ter impressões diferentes da mesma empresa. Isso significa que uma empresa pode apresentar indicadores de liquidez, endividamento ou rentabilidade muito diferentes, dependendo da demonstração que se está analisando, se a remetida à Bovespa ou à NYSE.
\end{abstract}

Sobre a Lei n. ${ }^{0} 11.638 / 07$ e o processo brasileiro de convergência a tais normas internacionais, Barbosa Neto et al. (2009) assim comenta: 
O efetivo início de processo de convergência no Brasil ao padrão contábil se deu a partir de 2008, para as sociedades abertas e demais empresas de grande porte, conforme determinado pela Lei $n{ }^{\circ} 11.638 / 07$. Tal fato induz aos usuários da informação contábil a atentarem para as mudanças que a convergência produz nas demonstrações contábeis.

Ainda sobre o processo de convergência, Azevedo (2009, p. 72):

A lei coloca como meta a harmonização das normas e práticas contábeis brasileiras às internacionais, com o objetivo não apenas de colocar o Brasil nos trilhos dessa tendência global, mas também de facilitar o acesso das empresas nacionais aos mercados externos e atrair capitais estrangeiros ao País. Outra preocupação fundamental foi a de segregar os princípios contábeis em relação às normas tributárias e legislações específicas.

O aumento de transparência, confiabilidade, acesso das empresas nacionais às fontes de financiamento externas são exemplos de quão importante tornam-se as normas internacionais e, principalmente, sua adequação e harmonização por parte de países como o Brasil. Sobre isso, diligência realizada por Yu; Qu (2009) revela que o processo de harmonização das normas internacionais elevou o nível da informação. Pesquisas empíricas, a partir de abordagens indutivas, como a realizada por Gaeremynck, Thornton e Verriest (2009) revelam que as informações contábeis tornam-se realmente mais úteis a partir da adoção das IFRS.

\subsection{Legislação Societária Brasileira}

Assim como em diversos ambientes econômicos no mundo, o Brasil também está na agenda de convergência às normas internacionais de contabilidade do IASB. Entretanto, por estar inserido em um contexto denominado legalístico, carece de regulamentação legislativa para incorrer em mudanças nas suas práticas contábeis.

A legislação societária brasileira foi originalmente regulamentada pelo vetusto Código Comercial de 1850 que, no tocante às sociedades anônimas no Brasil, dispunha, em seu art. 295:

As companhias ou sociedades anônimas, designadas pelo objeto ou empresa a que se destinam, sem firma social, e administradas por mandatários revogáveis, sócios ou não sócios, só podem estabelecer-se por tempo determinado, e com autorização do Governo, dependente da aprovação do Corpo Legislativo quando hajam de gozar de algum privilégio: e devem provar-se por escritura pública, ou pelos seus estatutos, e pelo ato do Poder que as houver autorizado. 
Em meio a um governo discricionário, foi promulgado o Decreto-Lei n. ${ }^{\circ} 2.627$, de 26 de setembro de 1940, trazendo em seu bojo as características e a natureza da sociedade anônima ou companhia, posto que, segundo Requião (1988) "a legislação anterior não mais condizia com as necessidades da conjuntura econômica nacional.”.

Em meados da década de 1970 (época do surgimento do FASB), tal texto legal já não condizia com as necessidades dos investidores e demais usuários daquele tempo. Surgiu então, em 15 de dezembro de 1976, a Lei n. ${ }^{\circ}$ 6.404, conhecida como a Lei das Sociedades por Ações, que teve como base, para sua elaboração, o Model Business Corporation Act (MBCA - Modelo Federal de Legislação Societária dos EUA), regulamentando as práticas contábeis no Brasil. As principais diferenças entre o Decreto-Lei n. ${ }^{\circ} 2.627 / 40$ e a Lei das S/A, é que esta sistematiza as técnicas e práticas contábeis

Sobre isso, Requião (1988, p. 14) expõe:

O propósito, confessadamente repetido pelos autores do projeto de reforma, como das próprias autoridades governamentais, foi o de criar a estrutura da grande empresa brasileira. Acusa-se, por isso, o sistema da lei atual de ter relegado a segundo plano a pequeno e a média empresas constituídas como sociedade anônima, fechada e personalista, e que representam a massa de sociedades mercantis hoje existentes no Brasil.

No Brasil, para que se pudesse trabalhar com a convergência das normas, fez-se necessária a edição e a emissão de uma lei devidamente chancelada pelo Congresso Nacional brasileiro a fim de iniciar o processo de convergência. Tal iniciativa foi tomada com o Projeto de Lei $n .^{\circ} 3.741$, de 2000 , que previu as mudanças nas normas contábeis.

Em 28 de dezembro de 2007, o Congresso aprovou o Projeto de Lei $.^{\circ} 3.741 / 00$, mais tarde promulgado como a Lei n. ${ }^{\circ} 11.638 / 07$, modificando dispositivos da Lei n. ${ }^{\circ} 6.404 / 76$, no que tange a procedimentos contábeis. O objetivo foi, claramente, o de encaminhar o Brasil para a convergência das normas internacionais de contabilidade. O grande problema foi a lentidão do processo burocrático brasileiro.

Sobre isso, elucidam ludícibus et al. (2009, p. 5-6):

Um problema sério surgiu do largo tempo que o então Projeto de Lei n. ${ }^{\circ}$ 3.741/00 levou o no congresso para se transformar na Lei n. ${ }^{\circ} 11.638 / 07$ : as normas internacionais evoluíram, e sofreram grandes modificações em função inclusive da adesão da União Europeia, mas o projeto de lei não capturou essas inovações. [...] buscando resolver rapidamente as dúvidas e pendências que o mercado e os próprios técnicos do Governo tinham, o governo editou a Medida Provisória n. ${ }^{\circ} 449 / 08$. Essa MP, digna de aplausos, representou um real e verdadeiro grande passo no sentido da convergência às Normas Internacionais de Contabilidade. 
A rigor, dita Medida Provisória 449, de 2008, foi convertida, em 27 de maio de 2009, na Lei $n .^{\circ} 11.941 / 09$, que, em conjunto com a Lei n. 11.638 , alterou os dispositivos contábeis da Lei n. ${ }^{\circ} 6.404 / 76$, além de aspectos tributários.

As alterações ocorridas na Lei das S/A, em função das duas últimas atualizações retrocitadas, são de suma importância para as empresas e as entidades que a elas são submetidas, uma vez que a nova legislação societária entrou em consonância com as normas internacionais de contabilidade, o que significa dizer que novos procedimentos contábeis haverão de ser adotados por parte dessas organizações para a elaboração e divulgação de suas informações econômico-financeiras. Tais critérios novos podem ocasionar aumento ou redução no valor de suas contas e, de conseguinte, na percepção que seus investidores possuem sobre elas.

\section{METODOLOGIA}

O estudo tem a finalidade de revelar o que acontece com as demonstrações contábeis das empresas do setor de petróleo, gás e biocombustíveis antes e após a atualização da legislação societária com as emissões das Leis $n$. ${ }^{\text {s } 11.638 / 07 ~ e ~ 11.941 / 09 . ~ A ~ i n t e n c ̧ a ̃ o ~ e ́ ~}$ levantar, analisar, classificar e comparar as informações contidas nas demonstrações contábeis das empresas da amostra entre períodos distintos e descobrir o nível de ajuste das empresas brasileiras ao padrão internacional de contabilidade. Em razão disso, a natureza de pesquisa deste trabalho é descritiva.

Sobre a natureza, Gil (2002, p. 19) assim define "[...] pesquisa descritiva: visa descrever as características de determinada população ou fenômeno, ou o estabelecimento de relações entre as variáveis. Envolve o uso de técnicas padronizadas de coleta de dados: [...] observação sistemática."

Dessarte, como se objetiva descrever as características da amostra, nesse caso, das características da informação contábil divulgada pela mesma, busca-se de forma natural incidir em uma pesquisa de forma qualitativa. Matias-Pereira (2007, p. 70-71), elucida sobre tal formato:

[...] pesquisa qualitativa: parte do entendimento de que existe uma relação dinâmica entre o mundo real e o sujeito, isto é, um vínculo indissociável entre o mundo objetivo e a subjetividade do sujeito que não pode ser traduzido em números. A interpretação dos fenômenos e a atribuição de significados são básicas no processo de pesquisa qualitativa. Não requerem o uso de métodos e técnicas estatísticas. O ambiente natural é a fonte direta para a coleta de dados e o pesquisador é o instrumento-chave. É descritiva. Os pesquisadores tendem a analisar seus dados indutivamente. O processo e seu significado são os focos principais de abordagem.

Doravante, para nortear a pesquisa, buscar-se-ão documentos secundários que ofereçam base aos conceitos propostos para o estudo. 
Tal pesquisa bibliográfica procurou fundamentar o que já foi referido sobre o tema, por meio da revisão de diversas literaturas que tratavam sob visões diferentes e que davam a conotação desejada para corroborar os assuntos, formando-os em cadeia.

A abordagem adotada foi a indutiva, partindo de análises particulares para a generalização. A análise, realizada em cada uma das entidades elencadas na composição da amostra, busca, em um primeiro momento, resultados individuais para os questionamentos.

Para Schroeder et al. (2009, p. 112. tradução livre), a "abordagem indutiva para pesquisas enfatiza observações feitas e desenha conclusões destas observações. Dessa maneira, esse método é descrito como 'indo do específico para o geral' porque o pesquisador generaliza sobre o universo das observações limitadas e situações específicas.".

Em termos procedimentais, este trabalho consistirá em analisar, por levantamento, as informações contidas nas demonstrações contábeis divulgadas publicamente na Bolsa de Valores antes da emissão da Lei $n .^{\circ} 11.638 / 07$, ou seja, as demonstrações datadas no exercício social de 2007. Posteriormente, serão analisadas, também por levantamento, as informações após a emissão da Lei n. ${ }^{\circ}$ 11.638/07 com as demonstrações datadas no exercício social de 2008.

A comparação consistirá em confrontar os dados anteriores com posteriores com base nas normas internacionais de contabilidade e nas 20 alterações ocorridas e adotadas pela legislação societária brasileira e assim interpretar as informações de modo a atender aos objetivos e pressupostos da pesquisa.

Quanto ao sujeito da pesquisa, o setor em comento conta com - segundo o sítio eletrônico do Instituto Brasileiro de Petróleo, Gás e Biocombustíveis (IBP), 194 empresas operando no Brasil em atividades de extração, produção e refino de petróleo; produção e comercialização de gás natural veicular, etc. Entretanto, o presente estudo tem como amostra apenas as companhias abertas que operam na Bovespa e, portanto, disponibilizam suas informações contábeis publicamente. Sua importância se deve, sobretudo, à quantidade de recursos operados, vital para a economia e para o mercado de capitais, e a concentração do elevado montante financeiro que se precisa para o segmento.

De conseguinte, o elenco de empresas que compõem a amostra é:

- Brasil Ecodiesel Indústria e Comércio de Biocombustíveis S.A.

- Novamarlim Participações S.A.

- Novamarlin Petróleo S.A.

- OGX Petróleo e Gás Participações S.A.

- Petróleo Brasileiro S.A. - Petrobras

- Refinaria de Petróleos Manguinhos S.A.

Obs.: A Novamarlin divulga em separado informações da Holding e sua subsidiária; para este trabalho será considerada a informação consolidada, ou seja, Novamarlin Participações S.A. e Novamarlin Petróleo S.A como uma única companhia. 
Pelo caráter da amostra intencional, o estudo não poderá servir para generalizações sobre o setor de petróleo, gás e biocombustível como um todo, mas terá importantes sinalizações sobre as mudanças ocorridas na divulgação de suas informações contábeis, uma vez que a amostra contempla as empresas listadas na Bovespa.

\section{ANÁLISE DOS DADOS}

\subsection{Descrição e Análise das Adequações às Novas Práticas Contábeis}

Inicialmente, são elencadas as alterações contábeis advindas das normas inter-nacionais de contabilidade em nível comparativo para cada empresa da amostra antes e depois da emissão das Leis n.os 11.638/07 e 11.941/09.

No Tabela.$^{0} 1$, pode-se observar a referida descrição comparativa cuja primeira coluna diz respeito às empresas da amostra; a segunda coluna, às práticas contábeis (contidas na Lei n. ${ }^{\circ}$ 6.404/76) que sofreram alteração das normas internacionais; e na terceira e quarta colunas, a inferência sobre a adequação ao referido padrão internacional antes e depois das emissões das leis. Ainda, para a terceira e quarta colunas, os dados foram assim processados:

- Sim: quando se pôde observar que houve adequação na íntegra à prática contábil internacional por parte de cada empresa.

- Sim, parcialmente: quando a empresa realizou parte da adequação devi-do à permissividade da legislação brasileira.

- Não: quando nenhuma adequação foi divulgada. e

- Não se aplica: quando tal prática não é adotada pela empresa e, portanto, não foi considerada na análise dos dados.

Obs.: Para maiores detalhes sobre o processamento dos dados infra, apêndices são encontrados ao final deste trabalho com o referido banco de dados extraído do sítio eletrônico da Bovespa pode ser visualizado no anexo.

Tabela 1: Comparativo de adequação às normas internacionais antes e depois das Leis

$$
\text { n. }{ }^{\text {os }} 11.638 / 07 \text { e } 11.941 / 09
$$

\begin{tabular}{|c|c|c|c|}
\hline Empresas & Práticas Contábeis Alteradas & $\begin{array}{l}\text { Antes das Leis n. }{ }^{\text {os }} \\
11.638 / 07 \text { e } 11.941 / 09\end{array}$ & $\begin{array}{l}\text { Depois das Leis n. }{ }^{\text {os }} \\
11.638 / 07 \text { e } 11.941 / 09\end{array}$ \\
\hline & Tributação & Não se aplica & Não \\
\hline & DFC & Sim & Sim \\
\hline & DVA & Não & Sim \\
\hline & Estrutura das contas patrimoniais & Sim, parcialmente & Sim, parcialmente \\
\hline & Resultados de Exercícios Futuros & Não se aplica & Não se aplica \\
\hline & Ações em Tesouraria & Não se aplica & Não se aplica \\
\hline & Lucros Acumulados & Não se aplica & Não se aplica \\
\hline
\end{tabular}




\begin{tabular}{|c|c|c|c|}
\hline \multirow{13}{*}{$\begin{array}{l}\text { Brasil } \\
\text { Ecodiesel }\end{array}$} & Ativo Diferido & Não & Sim, parcialmente \\
\hline & Ativo Intangível & Sim & Sim \\
\hline & Pesquisa e Desenvolvimento & Não & Sim \\
\hline & Arrendamento Mercantil & Não se aplica & Não se aplica \\
\hline & Reservas de Capital & Não se aplica & Não se aplica \\
\hline & Reservas de Reavaliação & Não se aplica & Não se aplica \\
\hline & Ajuste de Avaliação Patrimonial & Não & Sim \\
\hline & Instrumentos Financeiros & Não & Não \\
\hline & Estoques & Não & Não \\
\hline & Ajuste a Valor Presente & Não & Não \\
\hline & Teste de Recuperabilidade & Não & Sim, parcialmente \\
\hline & Participações Societárias & Não & Sim \\
\hline & Participações nos lucros & Não & Não \\
\hline \multirow{20}{*}{ Novamarlin } & Tributação & Não se aplica & Sim \\
\hline & DFC & Não & Sim \\
\hline & DVA & Não & Sim \\
\hline & Estrutura das contas patrimoniais & Sim, parcialmente & Sim, parcialmente \\
\hline & Resultados de Exercícios Futuros & Não se aplica & Não se aplica \\
\hline & Ações em Tesouraria & Não se aplica & Não se aplica \\
\hline & Lucros Acumulados & Sim & Sim \\
\hline & Ativo Diferido & Não se aplica & Não se aplica \\
\hline & Ativo Intangível & Não se aplica & Não se aplica \\
\hline & Pesquisa e Desenvolvimento & Sim & Sim \\
\hline & Arrendamento Mercantil & Não & Sim \\
\hline & Reservas de Capital & Não se aplica & Não se aplica \\
\hline & Reservas de Reavaliação & Não se aplica & Não se aplica \\
\hline & Ajuste de Avaliação Patrimonial & Não & Sim \\
\hline & Instrumentos Financeiros & Não & Não \\
\hline & Estoques & Não se aplica & Não se aplica \\
\hline & Ajuste a Valor Presente & Não & Sim \\
\hline & Teste de Recuperabilidade & Não & Sim, parcialmente \\
\hline & Participações Societárias & Não & Sim \\
\hline & Participações nos lucros & Não & Não \\
\hline \multirow{18}{*}{$\begin{array}{l}\text { OGX } \\
\text { Petróleo } \\
\text { e Gás }\end{array}$} & Tributação & Não se aplica & Sim \\
\hline & DFC & Não & Sim \\
\hline & DVA & Não & Sim \\
\hline & Estrutura das contas patrimoniais & Sim, parcialmente & Sim, parcialmente \\
\hline & Resultados de Exercícios Futuros & Não se aplica & Não se aplica \\
\hline & Ações em Tesouraria & Não se aplica & Não se aplica \\
\hline & Lucros Acumulados & Não & Sim \\
\hline & Ativo Diferido & Não & Sim \\
\hline & Ativo Intangível & Sim & Sim \\
\hline & Pesquisa e Desenvolvimento & Não & Sim \\
\hline & Arrendamento Mercantil & Não se aplica & Não se aplica \\
\hline & Reservas de Capital & Não se aplica & Não se aplica \\
\hline & Reservas de Reavaliação & Não se aplica & Não se aplica \\
\hline & Ajuste de Avaliação Patrimonial & Não & Sim \\
\hline & Instrumentos Financeiros & Sim, parcialmente & Sim \\
\hline & Estoques & Não se aplica & Não se aplica \\
\hline & Ajuste a Valor Presente & Não & Sim, parcialmente \\
\hline & Teste de Recuperabilidade & Sim & Sim \\
\hline
\end{tabular}




\begin{tabular}{|c|c|c|c|}
\hline & Participações Societárias & Não & Sim \\
\hline & Participações nos lucros & Não & Não \\
\hline \multirow{20}{*}{ Petrobras } & Tributação & Não se aplica & Sim \\
\hline & DFC & Sim & Sim \\
\hline & DVA & Sim & Sim \\
\hline & Estrutura das contas patrimoniais & Sim, parcialmente & Sim, parcialmente \\
\hline & Resultados de Exercícios Futuros & Não & Sim \\
\hline & Ações em Tesouraria & Não se aplica & Não se aplica \\
\hline & Lucros Acumulados & Sim & Sim \\
\hline & Ativo Diferido & Não & Não \\
\hline & Ativo Intangível & Sim & $\operatorname{Sim}$ \\
\hline & Pesquisa e Desenvolvimento & Sim & Sim \\
\hline & Arrendamento Mercantil & Não & Sim \\
\hline & Reservas de Capital & Não & Sim \\
\hline & Reservas de Reavaliação & Não & Sim \\
\hline & Ajuste de Avaliação Patrimonial & Não & Sim \\
\hline & Instrumentos Financeiros & Sim & Sim \\
\hline & Estoques & Não & Não \\
\hline & Ajuste a Valor Presente & Sim & Sim \\
\hline & Teste de Recuperabilidade & Sim & Sim \\
\hline & Participações Societárias & Não & Sim \\
\hline & Participações nos lucros & Não & Não \\
\hline \multirow{20}{*}{$\begin{array}{l}\text { Refinaria de } \\
\text { Petróleos } \\
\text { Manguinhos }\end{array}$} & Tributação & Não se aplica & Não \\
\hline & DFC & Não & Sim \\
\hline & DVA & Não & Sim \\
\hline & Estrutura das contas patrimoniais & Sim, parcialmente & Sim, parcialmente \\
\hline & Resultados de Exercícios Futuros & Não se aplica & Não se aplica \\
\hline & Ações em Tesouraria & Não & Sim \\
\hline & Lucros Acumulados & Não se aplica & Não se aplica \\
\hline & Ativo Diferido & Não & Sim \\
\hline & Ativo Intangível & Sim & Sim \\
\hline & Pesquisa e Desenvolvimento & Sim & Sim \\
\hline & Arrendamento Mercantil & Não se aplica & Não se aplica \\
\hline & Reservas de Capital & Não & Não \\
\hline & Reservas de Reavaliação & Não se aplica & Não se aplica \\
\hline & Ajuste de Avaliação Patrimonial & Não & Sim \\
\hline & Instrumentos Financeiros & Não & Não \\
\hline & Estoques & Não & Não \\
\hline & Ajuste a Valor Presente & Não & Sim, parcialmente \\
\hline & Teste de Recuperabilidade & Não & Sim \\
\hline & Participações Societárias & Não & Sim \\
\hline & Participações nos lucros & Não & Não \\
\hline
\end{tabular}

Fonte: Dados da pesquisa, 2010.

A Tabela 1 demonstra a seguir a proporção de respostas positivas no tocante à adequação das empresas às normas internacionais. Na primeira coluna, estão relacionadas às práticas contábeis; na segunda e terceira colunas, estão as proporções referentes 
a adequações antes e depois das legislações; e na quarta coluna, a variação do nível de convergência. Tal diferença resultou da Tabela 1.

Tabela 2: Proporção comparativa de adequação aos padrões internacionais

\begin{tabular}{|c|c|c|c|}
\hline Práticas Contábeis Alteradas & $\begin{array}{c}\text { Antes da Lei n. }{ }^{\circ} 11.638 / 07 \\
\text { e MP } 449 / 08\end{array}$ & $\begin{array}{c}\text { Depois da Lei } .^{\circ} 11.638 / 07 \\
\text { e MP } 449 / 08\end{array}$ & $\begin{array}{l}\text { Variação } \\
\text { Absoluta }\end{array}$ \\
\hline Tributação & $0 \%$ & $60 \%$ & $60 \%$ \\
\hline DFC & $40 \%$ & $100 \%$ & $60 \%$ \\
\hline DVA & $20 \%$ & $100 \%$ & $80 \%$ \\
\hline Estrutura das contas patrimoniais & $100 \%$ & $100 \%$ & $0 \%$ \\
\hline Resultados de Exercícios Futuros & $0 \%$ & $100 \%$ & $100 \%$ \\
\hline Ações em Tesouraria & $0 \%$ & $100 \%$ & $100 \%$ \\
\hline Lucros Acumulados & $67 \%$ & $100 \%$ & $33 \%$ \\
\hline Ativo Diferido & $0 \%$ & $75 \%$ & $75 \%$ \\
\hline Ativo Intangível & $100 \%$ & $100 \%$ & $0 \%$ \\
\hline Pesquisa e Desenvolvimento & $60 \%$ & $100 \%$ & $40 \%$ \\
\hline Arrendamento Mercantil & $0 \%$ & $100 \%$ & $100 \%$ \\
\hline Reservas de Capital & $0 \%$ & $50 \%$ & $50 \%$ \\
\hline Reservas de Reavaliação & $0 \%$ & $100 \%$ & $100 \%$ \\
\hline Ajuste de Avaliação Patrimonial & $0 \%$ & $100 \%$ & $100 \%$ \\
\hline Instrumentos Financeiros & $40 \%$ & $40 \%$ & $0 \%$ \\
\hline Estoques & $0 \%$ & $0 \%$ & $0 \%$ \\
\hline Ajuste a Valor Presente & $20 \%$ & $80 \%$ & $60 \%$ \\
\hline Teste de Recuperabilidade & $40 \%$ & $100 \%$ & $60 \%$ \\
\hline Participações Societárias & $0 \%$ & $100 \%$ & $100 \%$ \\
\hline Participações nos lucros & $0 \%$ & $0 \%$ & $0 \%$ \\
\hline Média & $24 \%$ & $80 \%$ & $56 \%$ \\
\hline
\end{tabular}

Fonte: dados da pesquisa, 2010.

Pode-se perceber, com base nos dados encontrados de adequação, um indicador de $56 \%$ no nível médio de adequação total. Muitas dessas adequações se dão em função da obrigatoriedade e muitas em função de divulgação voluntária.

Sobre divulgação voluntária, destaca-se o trabalho de Verrecchia (2001) quando o pesquisador levantou a tese sob três abordagens distintas: Divulgação Baseada em Associação (association-based disclosure); Divulgação Baseada em Julgamento (dis-cretionarybased disclosure) e Divulgação Baseada em Eficiência (efficiency-based disclosure).

Diversas empresas vêm demonstrando voluntariamente suas transações não obrigatórias, conforme é revelado em pesquisas de Murcia e Santos (2010), Eugénio (2010), entre outros.

A pesquisa de Aquino e Ferreira (2007) tem importância especial neste trabalho, pois faz referência à divulgação compulsória e não compulsória realizada pela Cia. Petrobras, revelando que, dos itens não obrigatórios, foi verificado um nível de divulgação maior que $75 \%$ das recomendações demonstradas pela pesquisa. 
Pesquisa realizada por Salotti e Yamamoto (2008) revela que, antes da emissão da Lei n. ${ }^{\circ} 11.638 / 07$, as companhias abertas com ações na Bovespa praticavam a divulgação voluntária principalmente pela preocupação com a percepção de seus investidores. Entre outros motivos, a pesquisa revelou que tais divulgações espontâneas ocorriam pelo bom desempenho econômicofinanceiro da companhia, baixo custo de divulgação e para reduzir a assimetria informacional.

Não só no Brasil, mas em todo o mundo, empresas vêm divulgando voluntariamente suas informações contábeis. Pesquisa realizada por Matoussi e Chakroun (2009) em companhias não financeiras listadas no mercado de capitais Tunisiano, no período de 2003 a 2005, revelou que a divulgação voluntária aumentou no decorrer do tempo. Revelou ainda que a independência, a estrutura do corpo diretor e o controle familiar não possuem correlação com a voluntariedade dos disclosures. Entretanto, foi observado que o bom gerenciamento e a qualidade na governança corporativa são representativos na evidenciação espontânea.

Essas sinalizações podem significar que as empresas, ao divulgarem espontaneamente informações de ordem econômico-financeira, atendem a exigências seja do mercado ou dos seus investidores.

Após a análise de todas as práticas contábeis que sofreram algum tipo de alteração advinda das normas internacionais de contabilidade, analisar-se-ão o nível geral de adequação por parte das empresas.

A Tabela 3 revela o nível de adequação sob a ótica das empresas aos padrões intemacionais.

Tabela 3: Proporção comparativa de adequação aos padrões internacionais para cada empresa

\begin{tabular}{|l|c|c|c|}
\hline \multicolumn{1}{|c|}{ Empresas } & $\begin{array}{c}\text { Antes da Lei } \mathbf{n} .^{\mathbf{0} 11.638 / 07} \\
\text { e MP 449/08 }\end{array}$ & $\begin{array}{c}\text { Depois da Lei n. }{ }^{\mathbf{1 1}} \text { 1.638/07 } \\
\text { e MP 449/08 }\end{array}$ & $\begin{array}{c}\text { Variação } \\
\text { Absoluta }\end{array}$ \\
\hline Brasil Ecodiesel & $23 \%$ & $64 \%$ & $41 \%$ \\
\hline Novamarlin & $25 \%$ & $85 \%$ & $60 \%$ \\
\hline OGX Petróleo e Gás & $31 \%$ & $93 \%$ & $62 \%$ \\
\hline Petrobras & $50 \%$ & $84 \%$ & $34 \%$ \\
\hline Refinaria de Petróleos Manguinhos & $20 \%$ & $69 \%$ & $49 \%$ \\
\hline Média & $\mathbf{3 0 \%}$ & $\mathbf{7 9 \%}$ & $\mathbf{4 9 \%}$ \\
\hline
\end{tabular}

Fonte: Dados da pesquisa, 2010.

Consoante se observa uma média de adequação na ordem de $30 \%$ antes das atualizações da legislação societária cuja média obteve considerável evolução após a tal modernização atingindo patamares na ordem de $79 \%$.

Pode-se observar das tabelas acima que a Cia. Petrobras, até o período de 2007, vinha com um nível de adequação a normativos internacionais, pelo menos, três vezes maior que as demais companhias do mesmo setor. Para o período de 2008, todas as empresas realizaram significativas adequações às normas internacionais de contabilidade. Interpretase consoante que a Petrobras parece ser a empresa que mais se preocupou com a compe- 


\section{repec}

titividade do mercado do setor com relação às demais, pelo me-nos no tocante ao nível de divulgação de informações contábeis.

Tal revelação corrobora com o resultado encontrado por Souza et al. (2008) quando, em pesquisa realizada em uma amostra de 107 companhias abertas do sul brasileiro, afirmam que as empresas investigadas ainda têm muito a progredir no que diz respeito à evidenciação de informações contábeis.

Ainda corroborando com o resultado encontrado nesse estudo, uma pesquisa revelada por Murcia e Santos (2010) apontou, com comprovação estatística, que empresas de maior lucratividade, tamanho e nível de auditoria divulgam mais e melhores informações do que as demais. A pesquisa foi aplicada nas 100 maiores companhias não financeiras abertas do Brasil nos períodos de 2006, 2007 e 2008.

Nesse sentido, evidências parecem apontar que, mesmo havendo preocupação por parte das empresas em se tornarem competitivas sob a ótica dos investidores de capital, muito precisou ser feito com o advento das Leis $n$. os 11.638/07 e 11.941/09 para se adequar às normas internacionais de contabilidade. Apenas a Petrobras apresentou evidências de que estava um passo a frente às demais empresas do setor no tocante ao nível de divulgação das informações contábeis, o que confirma os resultados de Murcia e Santos (2010).

\section{CONSIDERAÇÕES FINAIS}

O artigo estuda o seguinte problema de pesquisa: com a adequação da legislação societária brasileira aos padrões internacionais, qual o estágio de divulgação das informações contábeis em empresas do setor de petróleo, gás e biocombustíveis listadas na Bovespa?

Para contribuir à resposta da referida questão social, busca-se analisar o estágio de adequação da nova legislação societária brasileira às normas internacionais de contabilidade; avaliar as informações contábeis divulgadas pelo setor do petróleo, gás e biocombustíveis, relativas aos exercícios sociais de 2007 e 2008, e, baseando-se em um comparativo, elencar quais evoluções a nova legislação societária conferiu às informações contábeis divulgadas.

Para isso, é efetuado levantamento na Bovespa das demonstrações contábeis (Balanço Patrimonial, Demonstração do Resultado do Exercício, Demonstração dos Fluxos de Caixa, Demonstração do Valor Adicionado, Notas Explicativas, Parecer de Auditoria, Relatório da Administração entre outros) de 5 (cinco) companhias constantes no setor de petróleo, gás e biocombustíveis. Em seguida, foi realizada análise das 20 (vinte) práticas contábeis as quais as empresas realizaram algum de tipo de adequação às normas internacionais. Tal análise foi fundamentada em bibliografias específicas e, principalmente, em pesquisas positivistas cuja conotação foi científica através, inclusive, de comprovações estatísticas.

Os principais resultados encontrados neste estudo foram: 
a) Das 20 (vinte) práticas contábeis que sofreriam alterações com as Leis n.os 11.638/07 e 11.941/09 advindas das normas internacionais, 8 (oito) foram adotadas pela amostra desta pesquisa antes da emissão dos referidos normativos, da seguinte maneira: evidenciação de Ativos Intangíveis por $100 \%$ da amostra; não cumulação de lucros em conta específica por $67 \%$ da amostra; classificação de pesquisa e desenvolvimento como despesa por $60 \%$ da amostra; evidenciação da Demonstração dos Fluxos de Caixa por $40 \%$ da amostra; realização do teste de recuperabilidade por $40 \%$ da amostra; evidenciação da Demonstração do Valor Adicionado por $20 \%$ da amostra; avaliação de instrumentos financeiros a valor justo por $20 \%$ da amostra; adoção do ajuste a valor presente por $20 \%$ da amostra. O exposto representa uma média de adequação de $24 \%$ com relação ao total das práticas, conforme visualizado na Tabela 2 deste trabalho. A Petrobras realizou adequação das normas na ordem de $50 \%$, enquanto as demais companhias sujeito da pesquisa representaram uma média de $25 \%$ de adequação. Isso conclui, especificamente para este ponto, que a todas as companhias buscam de alguma maneira se antecipar na evidenciação das informações contábeis para se manterem competitivas no mercado estrangeiro. Conclui-se também que a Petrobras foi a empresa que mais buscou reduzir a assimetria informacional para com seus stakeholders e aumentar sua competitividade no mercado internacional, o que confirma os resultados do estudo de Murcia e Santos (2010).

b) Das vinte práticas contábeis que foram alteradas efetivamente na legislação so-cietária brasileira advindas das normas internacionais 11 (onze) foram 100\% adotadas pela amostra desta pesquisa após a emissão dos normativos societários, a saber: ela-boração e evidenciação da Demonstração dos Fluxos de Caixa e Demonstração do Valor Adicionado; reclassificação de Resultados de Exercícios Futuros; especificação de Ações em Tesouraria; não cumulação dos lucros em conta específica; evidenciação de Ativos Intangíveis; classificação de Pesquisas e Desenvolvimentos como despesas; prevalência da essência sob a forma no caso de arrendamentos mercantis; reclassificação e exclusão de reservas de reavaliação; adoção do ajuste de avaliação patrimonial; ponderação do conceito de coligadas em participações societárias. O teste de recuperabilidade foi adotado por $60 \%$ da amostra; o Ativo Diferido foi excluído e desconsiderado e as Reservas de Capital foram adaptadas por 50\% da amostra; instrumentos financeiros foram avaliados a valor justo e foram adotados os ajustes a valor presente por $40 \%$ da amostra. O exposto representa uma média de $80 \%$ de adequação, conforme visualizado na Tabela 2 deste trabalho. Ainda tratando o que foi revelado pela referida Tabela 2, após a emissão das Leis n.os 11.638/07 e 11.941/09, não só a Petrobras, mas todas as empresas do setor 
realizaram consideráveis adequações às normas internacionais, resultado este que contribui para a resposta do problema de pesquisa.

c) No tocante ao RTT, opção pelo regime tributário de transição, apenas as empresas lucrativas o adotaram facultativamente no ano de 2008 , levando a evidências que houve uma preocupação, por parte das empresas, de que os efeitos das novas regras contábeis aumentassem o valor de seus patrimônios e consequentemente seus impostos sobre a renda. Vale ressaltar que o RTT é obrigatório a partir do exercício de 2010.

d) Descritivamente, a Tabela 3 deste estudo apresenta a seguinte evolução em termos de convergência às novas regras contábeis brasileiras: a Cia. Brasil Ecodiesel pulou de $23 \%$ para $64 \%$ no nível de adequação; a Novamarlin foi de $25 \%$ a $85 \%$; a OGX Petróleo e Gás de 31\% para 93\%; já a Petrobras foi de $50 \%$ a $84 \%$; e a Refinaria de Petróleos Manguinhos saltou de $20 \%$ para uma adequação na ordem de 69\%. Conclui-se assim que, apesar de a lei não esgotar o direito, as empresas precisaram de substanciais adequações após as Leis n. os 11.638/07 e 11.941/09, com exceção da Petrobras, para se adequarem ao processo de convergência das normas internacionais de contabilidade.

Até certo nível, as empresas antecipam suas informações por meio de divulgação voluntária de dados contábeis no intuito de se manterem competitivas no mercado internacional e no setor sem necessariamente aguardarem o ordenamento jurídico para realizarem e evidenciarem suas práticas. Mesmo assim, os resultados deste trabalho parecem direcionar a conclusão de que as empresas com maior exposição no mercado de capitais internacional antecipam sua adequação a padrões internacionais de contabilidade em detrimento a companhias que não possuem o mesmo nível de desenvolvimento. Tal conclusão corrobora com os resultados encontrados por Souza et al. (2008).

Por fim, vale registrar que o posicionamento de competitividade adotado por essas empresas pode ser seguido como exemplo pelas demais companhias abertas brasileiras, visando ao aumento de transparência e redução de assimetria informacional perante investidores, através de informações contábeis com maior grau de fidedignidade.

De abordagem indutiva, as conclusões ora expostas neste trabalho não servem para generalizações sobre o nível de adequação de todas as companhias brasileiras de capital aberto às novas regras contábeis brasileiras no período de 2007/2008. Tal limitação ocorre em função de que apenas um dos diversos setores da Bovespa foi estudado. Porquanto, sugere-se que estudos sobre outros setores da economia brasileira sejam investigados para servir de comparativo a este estudo.

O foco deste trabalho é o de adequação às normas internacionais por parte das empresas brasileiras de capital aberto. Visando ampliar tal ponto de vista, a sugestão é de que 
futuros estudos sejam inquiridos sobre níveis de divulgação voluntária em comparação a exigências das novas regras contábeis no mesmo período.

Ainda, este estudo limitou-se à pesquisa qualitativa de natureza descritiva. Sugerese que o mesmo estudo seja realizado com uma amostra maior e em vários segmentos da economia à busca de resultados diversificados e comparativos a este.

Finalmente, estudos podem ainda ser realizados a cada uma das 20 (vinte) práticas aqui elencadas, analisando-se o nível de impacto que cada uma pode acarretar aos resultados/desempenhos das companhias brasileiras.

\section{REFERÊNCIAS}

AQUINO, Ducineli R. B. de. FERREIRA, Vanessa Florêncio. Análise do nível de evidenciação dos itens compulsórios e não compulsórios: um estudo nos relatórios contábeis da Petrobras. Revista Universo Contábil. Blumenau, v. 3, n. 1, p. 07-26, jan./abr., 2007.

AZEVEDO, Osmar Reis. Comentário às novas regras contábeis brasileiras. 3 ed. São Paulo: IOB, 2009.

BARBOSA NETO, João E. DIAS, Warley de O. PINHEIRO, Laura E. T. Impacto da Convergência para as IFRS na Análise Financeira: um Estudo em Empresas Brasileiras de Capital Aberto. Contabilidade Vista \& Revista. Belo Horizonte, v. 20, n. 4, p. 131-153, out./dez. 2009.

BOLSA DE MERCADORIAS \& FUTUROS; BOLSA DE VALORES DE SÃO PAULO BM\&FBOVESPA <http://www.bovespa.com.br/Principal.asp>. Acesso em 7 de setembro de 2009 às 09h.

BRASIL. Decreto-lei 2.627. Rio de Janeiro, 1940. . Lei 556. Rio de Janeiro, 1850. . Lei 6.404. Brasília: Senado Federal, 1976.

Lei 11.638. Brasília: Senado Federal, 2007. . Lei 11.941. Brasília: Senado Federal, 2009.

COMITÉ DE PRONUNCIAMENTOS CONTÁBEIS (CPC). Pronunciamento Conceitual Básico. Brasília: CPC, 2008.

ENERGY INSTITUTE ADMINSITRATION (EIA) <http://tonto.eia.doe.gov/country/country_ energy_data.cfm?fips=BR> acesso em dez./2009. 
ERNEST \& YOUNG. FIPECAFI. Manual de Normas Internacionais de Contabilidade: IFRS versus normas brasileiras. São Paulo: Atlas, 2009.

EUGÉNIO, Teresa. Avanços na Divulgação de Informação Social e Ambiental pelas Empresas e a Teoria da Legitimidade. Revista Universo Contábil. Blumenau, v. 6, n. 1, p. 102118, jan./mar., 2010.

FINANCIAL ACCOUNTING STANDARDS BOARD (FASB). Statements of Financial Accounting Concepts n. ${ }^{\circ}$ 01: Objectives of Financial Reporting by Business Enterprises. Connecticut: FASB, 1978.

GAEREMYNCK, Ann. THORNTON, Daniel B. VERRIEST, Arnt. Quality of IFRS Adoption. <http://ssrn.com/abstract=1266698> acesso em mar./2010.

GIL, Antonio Carlos. Como elaborar projetos de pesquisa. 4 ed. São Paulo Atlas, 2002. INSTITUTO BRASILEIRO DE GEOGRAFIA E ESTATÍSTICA (IBGE). <www.ibge.gov.br> acesso em dez./2009

INTERNATIONAL ACCOUNTING STANDARDS BOARD (IASB). IAS N. 01 - Presentation of Financial Statements. 2009.

dards. 2008.

IFRS N. 01 - First-Time Adoption of International Financial Reposting Stan-

IUDíCIBUS, Sérgio de. Teoria da Contabilidade. 9 ed. São Paulo: Atlas, 2009.

KLANN, Roberto Carlos. BEUREN, Ilse Maria. HEIN, Nelson. Impacto das Diferenças entre as Normas Contábeis Brasileiras e Americanas nos Indicadores de Desempenho de Empresas Brasileiras com ADRs. Brazilian Business Review. Vitória-ES, v. 6, n. 2, p. 154-173, mai./ago. 2009.

MATIAS-PEREIRA, José. Manual de metodologia da pesquisa científica. São Paulo: Atlas, 2007.

MATOUSSI, Hamadi. CHAKROUN, Raida. Board composition, ownership structure and voluntary disclosure in annual reports: evidence from Tunisia. International Accounting Congress (3rd) - IAAER/ANPCONT. USP: São Paulo, 2009. 
MURCIA, Fernando Dal-Ri. SANTOS, Ariovaldo dos. Determinants of Corporate Voluntary Disclosure in Brazil. <http://ssrn.com/abstract=1531767> acesso em mar./2010.

NIYAMA, Jorge Katsumi. Contabilidade Internacional. 1 ed. 5 reimpr. São Paulo: A-tlas, 2008. . SILVA, César A. Tibúrcio. Teoria da Contabilidade. São Paulo: Atlas, 2008.

REQUIÃO, Rubens. Curso de Direito Comercial. Vol 2. São Paulo: Saraiva, 1988.

SALOTTI, Bruno Meirelles. YAMAMOTO, Marina Mitiyo. Divulgação Voluntária da Demonstração dos Fluxos de Caixa no Mercado de Capitais Brasileiro. Revista de Contabilidade e Finanças. USP, São Paulo, v. 19, n. 48, p. 37-49, set./dez. 2008.

SCHROEDER. Richard G. CLARK, Myrtle W. CATHEY, Jack M. Financial Accounting Theory and Analysis. 9 ed. New Jersey: John Wiley \& Sons, 2009.

VERRECCHIA, Robert E. Essays on disclosure. Journal of Accounting and Economics. $n$ 32, p. 97-180, 2001.

YU, Yang. QU, Xiaohui. International accounting convergence in China: an empirical study of standards on assets measurement. International Accounting Congress (3rd) - IAAER/ANPCONT. USP: São Paulo, 2009. 